\title{
Conferência Nacional de Patologia e Recuperação de Estruturas
}

\author{
National Conference on Pathology and Recovery of Structures
}

Eliana Cristina Barreto Monteiro ${ }^{1}$ (D) orcid.org/0000-0003-0842-779X

Dione Luiza da Silva ${ }^{1}$ (D) orcid.org/0000-0002-2101-4511

Gabriela Alves Tenório de Morais ${ }^{1}$ (D) orcid.org/0000-0001-5132-0483

Regina Lúcia Melo de Oliveira ${ }^{1}$ (i) orcid.org/0000-0002-0859-0549

Klarissa Karen Tavares da Cruz ${ }^{1}$ (i) orcid.org/0000-0002-6630-4678

Bruna Ferraz Carvalho Dantas ${ }^{1}$ (i) orcid.org/0000-0001-8659-7634

${ }^{1}$ Departamento de Engenharia Civil, Universidade de Pernambuco, Recife, Brasil.

A Universidade de Pernambuco (UPE) é uma universidade pública estadual multicampi, formada por 15 unidades de ensino, dentre as quais está compreendida a Escola Politécnica de Pernambuco (POLI). A instituição constitui patrimônio da sociedade do estado e desde sua fundação, há 52 anos, desempenha papel crucial no desenvolvimento social e econômico no âmbito local.

Em 2016, a UPE promoveu o I Seminário de Patologia e Recuperação Estrutural - SEMIPAR. O evento reuniu profissionais e estudantes de diversos estados brasileiros. Em virtude do grande sucesso da primeira edição, em 2017, o evento ganhou caráter mais abrangente, passando a ser denominado Conferência Nacional de Patologia e Recuperação de Estruturas - CONPAR.

A CONPAR foi realizada nos dias 30 e 31 de agosto de 2017 e representou uma importante oportunidade para fomentar novos conhecimentos, técnicas e tecnologias, através da troca de experiências de profissionais da indústria da construção civil e da divulgação de pesquisas científicas relacionadas à patologia das edificações e à recuperação de estruturas. O evento foi organizado por uma comissão composta por 20 alunos de graduação e pós-graduação do curso de engenharia civil, sob a coordenação das professoras Eliana Cristina Barreto Monteiro (UPE) e Dione Luiza da Silva (UPE).

De caráter nacional, a Conferência foi aberta aos profissionais da área, estudantes da POLI e demais instituições brasileiras e contou com a participação de 400 inscritos. Ademais, foram submetidos 102 artigos científicos, dos quais 82 foram aprovados para publicação. Dentre os aprovados, os 20 melhores artigos foram escolhidos para publicação numa edição especial da Revista de Engenharia e Pesquisa Aplicada (REPA). Para aprovação, os trabalhos foram avaliados por pares por uma comissão científica composta por 31 mestres e doutores na área.

A temática dos trabalhos foi relacionada à patologia das edificações e à recuperação estrutural, e foram elaborados abordando os seguintes tópicos: 
- Manifestações patológicas em estruturas de concreto;

- Causas das manifestações patológicas em estruturas de concreto;

- Ensaios para inspeção e diagnóstico das estruturas de concreto;

- Métodos e materiais de inspeção, reabilitação e reforço de estruturas;

- Métodos de prevenção e controle das manifestações patológicas.

A apresentação dos trabalhos foi dividida em 04 sessões, nos formatos oral e pôster. Nas quais os trabalhos foram avaliados por uma banca examinadora composta por acadêmicos especialistas na área e os melhores trabalhos apresentados foram premiados. As apresentações tiveram como objetivo cardinal permitir maior desenvolvimento acadêmico e profissional do conferencista, através do fortalecimento do seu conhecimento técnico acerca de uma vertente tão importante da engenharia civil.

Diante do exposto, é com imensa satisfação que disponibilizamos ao público geral, através da Revista de Engenharia e Pesquisa Aplicada - Edição especial, importante veículo de disseminação do conhecimento científico, uma mostra dos melhores trabalhos da CONPAR 2017.

Por fim, não poderíamos deixar de agradecer ao comitê técnico da CONPAR pelo trabalho cuidadoso na edição deste volume. 